\title{
Ativismo feminino no movimento sindical rural de Sergipe/Brasil: (in)confidências de gênero' ${ }^{1}$
}

\author{
Márcia Santana Tavares²; Magaly Nunes de Góis ${ }^{3}$
}

\section{Resumo}

Neste artigo percorremos a trajetória de cinco mulheres que exerceram ou exercem cargos de gestão em sindicatos rurais de Sergipe e, a partir de uma releitura de gênero, buscamos identificar e analisar os desafios, mudanças, permanências e estratégias ensaiadas por elas desde os anos 1980 no enfrentamento às desigualdades de gênero. A incorporação das discussões de gênero no movimento sindical instrumentaliza as trabalhadoras rurais para que: a) assumam cargos de liderança nos sindicatos, a recusar o papel de coadjuvantes e a enfrentar as desigualdades de gênero; b) intensifiquem as lutas direcionadas à visibilidade de suas demandas e inclusão nas plataformas das políticas públicas e ao acesso a direitos sociais; c) busquem desestabilizar as representações de gênero construídas em torno dos papeis e funções tidos como femininos, que ainda mantêm tantas mulheres apartadas da luta sindical, de instâncias decisórias e de poder.

Palavras-chave: ativismo feminino; sindicatos rurais; gênero.

\section{Female activism in the rural union movement in Sergipe/Brazil: gender (in) confidences}

\footnotetext{
1 O presente artigo faz uma homenagem a Maria Lúcia Santos Moura, trabalhadora rural e histórica ativista do movimento sindical rural sergipano e brasileiro, primeira mulher a assumir a presidência de uma federação de trabalhadores/as na região Nordeste e uma companheira com quem compartilhamos a construção desse trabalho, que faleceu em janeiro de 2020.

2 Universidade Federal da Bahia, Assistente Social e Doutora em Ciências Sociais. Email: marciatavares1@mail.com.

3 PRONESE, Assistente Social e Doutora em Educação. E-mail: magalyngois@gmail.com.
}

GT 14 - Gênero, trabalho e sindicalismo 


\begin{abstract}
In this article, we cover the trajectory of five women who held or hold management positions in rural unions in Sergipe and, from a gender rereading, we seek to identify and analyze the challenges, changes, permanence and strategies they have tried since the 1980s copin with gender inequalities. The incorporation of gender discussions in the union movement provides rural workers with the tools to: a) assume leadership positions in unions, to refuse the role of assistants and to face gender inequalities; b) intensify the struggles aimed at the visibility of their demands and inclusion in public policy platforms and access to social rights; $c$ ) seek to destabilize the gender representations built around the roles and functions considered to be feminine, which still keep so many women away from union struggle, decision-making bodies and power.
\end{abstract}

Keywords: female activism; rural unions; genre.

\title{
Trilha percorrida
}

Começamos nossa trilha explicando as razões de nosso interesse pelo ativismo feminismo no movimento sindical rural e apresentando nossas companheiras de caminhada de construção e reconstrução de trilhas e como chegamos até elas.

A primeira razão reside na existência de lutas e movimentos sociais e sindicais por melhores condições de vida e de trabalho no campo que trazem como motes o acesso aos meios de produção e aos serviços essenciais a produção e reprodução da vida no campo, materializados pela democratização e universalização da propriedade da terra e da água e pelo acesso a serviços e benefícios necessários a permanência das/os trabalhadoras/es no campo: crédito, equipamentos e insumos agrícolas, assistência técnica, extensão rural, saúde, assistência social, previdência, educação, cultura, lazer, segurança alimentar e nutricional, saneamento e habitação.

A segunda razão se localiza na afirmação e reafirmação teórica revisão de literatura - e prática - narrativas das mulheres - de que apesar da histórica presença no campo de lutas e movimentos sociais, 
da ampliação da participação de mulheres nessas lutas e da existência de movimentos organizados e coordenados por mulheres, o trabalho no campo ainda é regido por uma forte divisão sexual que estabelece relações de trabalho desiguais entre homens e mulheres, fazendo com que o trabalho feminino permaneça invisível e desvalorizado, tanto no que se refere às atividades produtivas como reprodutivas.

A terceira razão está nas nossas intencionalidades que são: refletir sobre o processo de mobilização e engajamento das mulheres nas lutas e movimentos rurais e, em particular, na gestão do movimento sindical rural e na inserção nas diretorias dos sindicatos a partir de uma releitura de gênero; analisar as estratégias construídas desde os anos 1980 para enfrentamento e superação das desigualdades de gênero, engajamento nas lutas empreendidas pelos sindicatos e movimentos sociais populares e incorporação da discussão sobre as desigualdades de gênero pelos movimentos sociais e entidades sindicais rurais; identificar mudanças, desafios e permanências presentes nessas lutas e movimentos.

Tivemos como companheiras de caminhada cinco trabalhadoras e lideranças rurais sergipanas. Chegamos até elas por meio da Comissão Ampliada da Marcha das Margaridas e da Secretaria de Mulheres Trabalhadoras Rurais da Federação dos Trabalhadores na Agricultura do Estado de Sergipe (FETASE) que juntas mapearam os sindicatos que têm mulheres em suas diretorias executivas, na condição de presidenta e tesoureira, apontaram para a primeira presidenta de uma federação de trabalhadores rurais das nove federações da região Nordeste e para a primeira trabalhadora rural a assumir um cargo na Confederação Nacional dos Trabalhadores na Agricultura (CONTAG) e viabilizaram os encontros com essas mulheres realizados em três momentos:

1. O primeiro na sede da federação com Maria Aires Oliveira Nascimento, secretária de Mulheres Trabalhadoras Rurais e coordenadora da Comissão Ampliada da Marcha das 
Margaridas, quando da realização da entrevista, e residente no município de Poço Verde.

2. O segundo no Centro de Treinamento Sindical Rural (CENTRESIR), quando da realização de um encontro com as diretorias executivas dos sindicatos, momento em que conhecemos a história de luta de Maria Lúcia Santos Moura, expresidenta da Fetase e ex da Secretaria Nacional da Terceira Idade da Contag que vivia no município de São Cristóvão, e de duas presidentas dos Sindicatos de Trabalhadores e Trabalhadoras Rurais (STTR) dos municípios de Nossa Senhora Aparecida, Ana Paula Oliveira, e Feira Nova, Luciana dos Reis Santos.

3. O terceiro encontro possibilitou conhecermos a história da primeira trabalhadora rural a assumir um cargo na CONTAG, Gedalva Fonseca, que mora no município de Nossa Senhora de Socorro.

Nos encontros convidamos as mulheres a falarem sobre a inserção das trabalhadoras rurais no movimento sindical, as estratégias adotadas para ocuparem posições de direção e para enfrentar as desigualdades de gênero e os desafios e as conquistas presentes nessa caminhada, à luz das experiências vivenciadas por elas. Com vista a assegurarmos todas as riquezas presentes nas trajetórias de luta e de resistência dessas mulheres, os encontros foram realizados individualmente e gravados com sua autorização.

Ressaltamos que os nomes e os lugares ocupados por nossas companheiras de caminhada estão revelados porque lhes perguntamos se gostariam que seus nomes e lugares ocupados no movimento sindical fossem revelados no artigo em construção e todas responderam afirmativamente, por entenderam que sua identificação é uma forma de dar visibilidade não apenas às lutas das mulheres rurais, mas, às suas protagonistas, que têm nomes e histórias pessoais e coletivas. 
No meio da trilha sentimos necessidade de fazer uma breve apresentação sobre Sergipe e a estrutura do Movimento Sindical de Trabalhadores e Trabalhadoras Rurais (MSTTR), lugares de vivências e de lutas nos âmbitos privado - a casa e a família - e público - o mundo do trabalho (a roça) e o mundo sindical de nossas companheiras de caminhada.

Sergipe é o menor estado brasileiro, com uma área territorial de $21.925,424 \mathrm{~km}^{2}$, população estimada de 2.068 .017 pessoas distribuídas em 75 municípios e na área urbana, espaço onde vivem aproximadamente $1.500 .000 / 73,5 \%$ pessoas e na área rural/campo lugar de vida de um pouco mais de $500.000 / 26,5 \%$. A população sergipana é composta majoritariamente por negras e negros, considerando que $63 \%$ e $5 \%$ se autodeclararam pardas/os e negras/os, respectivamente; $30 \%$ declaram ser brancas/os e $1 \%$ outras/os. O Estado tem uma população feminina maior do que a masculina, pois $51,4 \%$ são mulheres e $48,6 \%$ são homens. Possui um Índice de Desenvolvimento Humano (IDH) de 0,665 , ocupando a $20^{a}$ posição dentre as 27 unidades federativas (BRASIL, 2010).

Considerando os critérios da Política Nacional de Assistência Social (BRASIL, 2004), a maioria dos municípios sergipanos são de pequeno porte, com população de até 50.000 habitantes, totalizando 69 municípios, que correspondem a $92 \%$ dos municípios. Deste universo, $52 / 69 \%$ têm até 20.000 habitantes e $17 / 23 \%$ contam com uma população de até 50.000 pessoas; $4 / 5 \%$ municípios são de médio porte, com população até 100.000 habitantes e $2 / 3 \%$ são de grande porte por terem uma população entre 100.001 e 900.000 habitantes. Os municípios espaços de vivência e de luta de nossas companheiras de caminhada são de grande porte: Aracaju e Nossa Senhora do Socorro; médio porte, São Cristóvão e, de pequeno porte Nossa Senhora Aparecida e Malhador.

O Movimento Sindical de Trabalhadores e Trabalhadoras Rurais (MSTTR), lugar de resistência e de luta dessas cinco ativistas é formado 
por: a) uma entidade nacional, a Confederação Nacional dos Trabalhadores na Agricultura (CONTAG), com atuação política e sindical, por meio das federações estaduais, nos 26 estados brasileiros e no Distrito Federal; b) a Federação dos Trabalhadores na Agricultura do Estado de Sergipe (FETASE) está presente nos 75 municípios sergipanos. Presença materializada pela localização de sua sede na capital do estado - Aracaju -, pela existência de 72 sindicatos municipais de trabalhadores e trabalhadoras rurais e duas bases sindicais em dois municípios, distribuídos em cinco polos sindicais - Baixo São Francisco (15 STTR), Centro Sul (17 STTR), Cotinguiba (16 STTR), Sertão (12 STTR) e Sul (14 STTR) (FETASE, 2019a); c) uma Coordenação Nacional e a Secretaria Estadual de Mulheres Trabalhadoras Rurais na estrutura da Contag e da federação e, de coordenações de mulheres trabalhadoras rurais em todos os sindicatos.

Finalizamos nossa trilha apresentando os passos dados e os resultados obtidos. No primeiro passo refletimos sobre a participação das trabalhadoras rurais no movimento sindical e as estratégias adotadas no enfrentamento das desigualdades de gênero. No segundo dialogamos sobre o ativismo feminino do movimento sindical rural à luz das narrativas das cinco ativistas sindicais. $\mathrm{O}$ apontamento dos desafios, mudanças e permanências presentes no ativismo feminino constitui o terceiro e último passo trilhado.

\section{A participação das trabalhadoras rurais no movimento sindical: estratégia de enfrentamento às desigualdades de gênero}

O engajamento das trabalhadoras rurais no movimento sindical não ocorreu por acaso, é parte de um processo de luta pela terra e por reconhecimento do seu trabalho, visto que em unidades agrícolas familiares, sua lida no campo tinha um caráter complementar, ou seja, não se configurava como trabalho, mas sim, "ajuda" ao chefe da família - pai, marido -, ou como coloca uma ex-presidente da FETASE, nos 
sindicatos se fazia referência à mulher pelo "nome meio chato que era 'companheira que ajudava o marido'", o que instituía sua invisibilidade no âmbito da organização do processo produtivo. Conforme argumenta Aires Oliveira:

A inserção das mulheres no movimento sindical surge na década de 60 para 70 sobre uma reivindicação das mulheres em lutar pela terra... a condição que as davam em se manter no campo, mas também reproduzir seu modo de vida. Naquela época a luta propriamente dita era pela terra e pela condição de sindicalizar-se, que a gente não tinha esse direito. A gente era sindicalizada como companheira ou como irmã ou filha. Eram as únicas condições que nos davam direito de ter o nome na carteirinha do sindicato. Não era nossa filiação: ou era esposa ou era a companheira ou era filha de fulano de tal. Fora isso, a gente não tinha condição. A luta das mulheres surge mais na perspectiva de sermos reconhecidas profissionalmente, inclusive pelo direito de se aposentar [...] A gente só reconhece o homem, o membro da família, o pai, o varão, o chefe de família... É só o homem. E aí surge na perspectiva da luta pelo direito e as mulheres emergem no movimento sindical e começam a se organizar. E aí a gente se sindicaliza com influência muito forte do movimento das mulheres trabalhadoras do Nordeste, já também frutos de um processo da organização sindical que aconteceu de outras mulheres fora do Brasil inspirada na luta da Marcha Mundial (AIRES OLIVEIRA).

Carneiro e Teixeira (1995), ao deslindarem as imagens de mulheres rurais em diferentes publicações, identificaram unicidade nos discursos, independentemente de serem emitidos por técnicos, assessores de ONGs, de sindicatos, da CUT ou mesmo sindicalistas. Mais revelador ainda é o fato de que a análise do discurso das mulheres rurais é circunscrita às sindicalistas, uma vez que só elas adquirem a condição de sujeitos, enquanto as demais mulheres permanecem 
invisíveis. Ainda conforme as autoras, isso é decorrente da visão equivocada e conservadora dessas entidades, para as quais as mulheres só adquirem visibilidade quando transformadas em sujeito coletivo. Em suma, as mulheres só se tornam visíveis por meio da sindicalização ou de formas de organização similares.

Com efeito, pondera Thayer (2001), até meados dos anos 1980 as mulheres não podiam assumir a condição plena de membro dos sindicatos e, o acesso a benefícios do governo como pensões ou programas de combate aos efeitos da seca eram provenientes de sua relação com o chefe (masculino) de família. Desse modo, muitas mulheres introjetaram e outras tantas ainda internalizam essa condição de inexistência enquanto produtoras de valores de troca. Em outras palavras, o trabalho no campo é desconsiderado por elas enquanto tal, assim como os muitos afazeres domésticos também o são, o que as leva a se convencerem de que não fazem nada, apenas "ajudam" 4 , embora lavem, passem e cozinhem, cuidem dos filhos, cultivam hortas e criam pequenos animais no entorno da casa, além de trabalharem na roça com o companheiro e filhos. Não é à toa, portanto, que trabalhadoras rurais baianas entrevistadas por Franco (2018) nomeiem o homem, chefe de família de "cumeeira da casa", pilar que sustenta, provedor econômico sem o qual a casa/família desmorona e não sobrevive.

Conforme lembra Lúcia Moura, até os anos 1980, o homem era sócio do sindicato e a mulher era sua dependente. Logo, a única possibilidade de a mulher se associar ao sindicato era não ter marido, situação que começa a mudar apenas em meados de 1980, quando as mulheres, principalmente nordestinas, começaram a se organizar e reivindicar uma participação mais ativa nos sindicatos. Ela nos conta que:

\footnotetext{
${ }^{4}$ Concordamos com Menezes e Almeida (2013) de que o uso do termo "ajuda" subtrai o valor do trabalho dispendido nas tarefas domésticas.
} 
Isso demorou muito tempo. Mesmo com a compreensão de ajudar o marido elas iam para lá escondidas porque não podiam participar disso tinham que ficar em casa, porque eram as responsáveis pela comida, por lavar as roupas no final de semana enfim. Mas muitas que foram declaradas, as mulheres mais ousadas, começaram a aparecer, pouquinhas, meio que receosas, mas começaram a aparecer não para de bater para dar opinião nas assembleias, mas para ouvir um pouco e tomar o gosto por isso. [...] Não foi fácil porque eram pouco os maridos que aceitavam, mas tinha as ousadas que fizeram esse debate e graças a isso a gente tem hoje muitas mulheres que são militantes. É de dar inveja são mulheres guerreiras são mulheres que defendem o que querem (LÚCIA MOURA).

A participação das mulheres nos sindicatos aconteceu paulatinamente, em Pernambuco ${ }^{5}$, Rio Grande do Norte, estendendo-se para outros estados à medida que as mulheres se organizavam e inspiravam outras para seguirem seus passos. Inicialmente, assumem funções mais burocráticas e sem poder decisório, fazendo uso dos supostos atributos naturais femininos, até "conquistarem espaços" e galgarem postos nas diretorias, desde tesoureiras até presidentas, conforme relata Ana Paula Oliveira:

Eu sou a primeira presidente do sindicato de Nossa Senhora de Aparecida que é mulher; anteriormente só tinha havido homens. E lá foi uma questão burocrática da própria diretoria porque tinha a questão da previdência. A previdência ela nos últimos tempos vem se digitalizando, então as mulheres têm mais paciência, se colocam. 'Ah, porque você tem mais paciência, tem jeito de

\footnotetext{
5 O movimento das trabalhadoras rurais em Pernambuco surgiu no início dos anos 1980, quando uma assessora da Federação de Trabalhadores na Agricultura do Estado (Fetape), na região do sertão central, começou a questionar a falta de participação das mulheres nos assuntos sindicais. Seu trabalho de mobilização a levou às casas isoladas dos agricultores, e ela começou a arregimentar mulheres, tirando-as das cozinhas e da zona de vigilância dos maridos, e colocando-as em contato com outras mulheres.
} 
conversar com as pessoas'. Para ser sincera, eu aproveitei esse espaço, porque se eu poderia me empoderar ali e ganhar espaço, então eu acho que veio muito dessas questões, essa coisa da qualificação.

As mulheres fizeram uso de pretensos atributos inatos, a paciência, organização e a "letra mais bonitinha" que as ajuda a lidar com questões burocráticas (atas, relatórios etc.), capacidade de escuta, de diálogo e, tornaram-se uma espécie de "faz-tudo do sindicato". Ao se descobrir tão capaz quanto os homens, "a mulher do movimento sindical de Sergipe agarrou as cotas e começou a aprimorar mais, a ter mais conhecimento e se empoderou mais nesses cargos das direções do sindicato por ter coragem de fazer esse enfrentamento" (Ana Paula Oliveira). Em outras palavras, as mulheres formaram um grupo coeso e organizado, mas também qualificado6, cujos argumentos consistentes lhes dava credibilidade e reconhecimento. Ana Paula Oliveira, destaca ainda que: "Não é só questão de se impor, tem que ser uma pessoa que tenha carisma", ao que acrescentamos, também, persistência e intrepidez, como revela o depoimento de Gedalva Fonseca, ao abordar os obstáculos colocados pelos homens para se associar ao sindicato e, em seguida, a discriminação enfrentada na condição de primeira mulher a assumir um cargo na CONTAG:

Quando foi com [quando tinha a idade de] 30, em 1973, em outubro de 73 eu entrei no movimento sindical como associada. Mas foi a maior dificuldade porque os sindicalistas, os presidentes, não queriam mulher no sindicato: 'só é os homens [sic]; não, a senhora não, é [só] seu marido'. Aí eu disse: 'mas meu marido não quer. Ele trabalha de pedreiro, eu sou quem trabalha na roça. Eu vou querer me associar para ter alguma coisa, algum direito a gente

\footnotetext{
${ }^{6}$ Cabe ressaltar que a participação mais efetiva das mulheres nas direções dos sindicatos está relacionada ao seu engajamento e militância em movimentos sociais, partidos políticos, movimentos vinculados à Igreja Católica (catequeses, pastorais) ou associações de agricultores (AMORIM et al, 2010).
} 
vai ter mais para frente'. Aí eles: 'mas não pode, não pode'. E eu insistia, insistia... até que eu entrei no sindicato como associada (GEDALVA FONSECA).

Eu tinha 33 anos. Fui muito discriminada pelos companheiros, eles parecem que estavam me testando. Nessa comissão provisória de mulheres a gente fazia os relatórios, fazia as propostas... porque tinha que passar pelo conselho da Contag. Os relatórios a gente levava para ser aprovados no dia da reunião do conselho. Quando eu assumi a direção da Contag como suplente, [Na foto de posse]. Eu fiquei no último degrau e aí quando bateram a foto só apareceu um lado do meu rosto. E eu no último degrau... quer dizer: última suplente, último degrau... e uma banda do meu rosto que apareceu. (GEDALVA FONSECA)

Carneiro (1994) coloca que embora não houvesse qualquer impeditivo legal à filiação feminina aos sindicatos rurais, várias diretorias eram contrárias e criavam empecilhos para desestimular as mulheres a se associarem. $\mathrm{O}$ ativismo feminino conseguiu que no IV Congresso da Contag, realizado em 1985, fosse finalmente aprovado um documento reconhecendo a mulher como trabalhadora rural bem como estabelecidas de pagamento de mensalidade que não comprometessem a renda familiar, um dos principais argumentos usados pelos opositores da filiação feminina.

O depoimento de Gedalva Fonseca reforça as colocações feitas por Ana Paula Oliveira quanto aos desafios enfrentados pelas mulheres não só para ingressarem como para assumirem funções de maior responsabilidade e poder decisório no âmbito dos sindicatos e órgãos de classe. Afinal, conforme aborda Toledo (2008), o movimento sindical é marcado pelo machismo, que contribuiu para tornar os sindicatos um lugar proibido para a mulher. Esse é um problema que tanto produziu cisão entre os trabalhadores como contribuiu para afastar as mulheres dos sindicatos e, ainda permanece como um elemento inibidor da 
participação feminina nas organizações sindicais. Mas, ao que parece, o ativismo feminino no movimento sindical rural é um caminho sem volta, conforme revelam os depoimentos sobre os quais nos deteremos no próximo tópico.

\section{Ativismo feminino no movimento sindical rural: narrativas de cinco ativistas sindicais do mundo rural sergipano}

$\mathrm{O}$ ativismo feminino no âmbito rural surge a partir da luta das mulheres por direitos, a exemplo do salário-maternidade, cuja demanda as conduz ao sindicato, impulsiona sua filiação e participação de algumas delas nas assembleias e ações promovidas pelo sindicato. De acordo com Aires Oliveira, então secretária de mulheres trabalhadoras rurais, é nesses momentos que se identifica sua disponibilidade e capacidade de liderança, primeiros passos para o ingresso das mulheres nas direções dos sindicatos, das federações e, mais adiante, na Contag, presença que se consolida com o estabelecimento da cota mínima de $30 \%$ de participação feminina nos sindicatos estabelecida pela CUT. Ao fazer uma retrospectiva das lutas empreendidas pelo ativismo feminino desde seus primeiros atos, explica:

De lá para cá a gente tem trazido a vida das mulheres e o contexto social como pautas que o movimento sindical defende. A gente começou com a luta pela terra foi até o direito previdenciário mas a gente percebeu que não são só essas faltas que dá conta e que as mulheres busca em seu empoderamento e que saiam das amarras sob o jugo do machismo. Quando a gente percebeu que nós mulheres somos sujeitos de direito do campo a gente também percebeu a necessidade de buscar e viabilizar condição de viver. A gente lutou para conquistar o crédito no Pronaf 
Mulher, que passa a ser uma política pública por uma pressão muito forte dos movimentos camponeses - e aí a Contag protagoniza essa organização. A gente luta também por acesso à água porque a gente sabe que o gerenciamento da água do quintal da casa é das mulheres na produção de alimentos saudáveis. A gente luta pela saúde que reconheça a integralidade do corpo da mulher, não vejo a mulher somente como peito e útero, processo da reprodução machista, a forma do governo dominar os nossos corpos. A gente lutou muito na marcha das margaridas por uma política integral da Saúde da mulher, que vai desde a sua mente até os outros membros do corpo. E sobretudo o enfrentamento à violência contra a mulher no campo, nos lares familiares (AIRES OLIVEIRA).

O retrospecto de Aires Oliveira aponta para a formação de uma identidade política feminina cujas raízes estão fincadas na luta por direitos elementares, a exemplo do direito previdenciário, acesso à terra, à água, desenvolvimento sustentável, soberania alimentar entre outros. De acordo com o Caderno de Textos para Estudos e Debates, no Eixo 4 - Autonomia econômica: trabalho e renda, formulado para embasar a preparação da Marcha das Margaridas 2015:

As mulheres questionam as bases do atual modelo de desenvolvimento, que é excludente e discriminatório. Queremos um desenvolvimento pautado na sustentabilidade ambiental, na inclusão econômica e social, que promova relações justas de trabalho e assegure igualdade de condições para as mulheres trabalhadoras.

Todavia, a mobilização das mulheres, conforme a própria Aires Oliveira ressalta, estende-se para questões de ordem subjetiva, que envolvem a hierarquia e assimetria que rege as relações de gênero na área rural, onde os valores patriarcais ainda se encontram fortemente arraigados e legitimam o controle e apropriação do homem sobre o corpo feminino, cujo exercício da sexualidade é disciplinado pelo 
homem, segundo sua vontade e desejos. Por conseguinte, a dominação sobre as mulheres encontra terreno fértil para diferentes formas de opressão, dentre elas a violência masculina contra as mulheres e meninas no âmbito doméstico e familiar (SAFFIOTI, 2004).

O Eixo 6 - Violência sexista do Caderno de textos acima mencionado situa a raiz da violência contra as mulheres no sistema patriarcal e no capitalismo, que determinam a necessidade de controle, objetificação e exploração do corpo feminino, mas também da vida e sexualidade das mulheres. $O$ patriarcado nega às mulheres a condição de sujeitos e donas de si, ao mesmo tempo em que as torna propriedades dos homens, a quem devem obediência no eito e na cama.

Outro questionamento do movimento organizado diz respeito ao Pronaf ${ }^{7}$ que, embora seja uma das primeiras políticas públicas voltadas aos agricultores familiares e que, portanto, deveria contemplar todas as pessoas de referência da família, a adesão e a gestão dos recursos se concentravam nos homens. Apenas em 2003 foi criada uma linha específica para as mulheres, o Pronaf Mulher8, com a finalidade de reduzir a desigualdade de gênero, quanto ao acesso à política de crédito rural e, com isso, ampliar a participação feminina na própria atividade produtiva, contribuindo para desnaturalização da divisão sexual e social desigual do trabalho no meio rural, mas também para aumentar a participação das mulheres em grupos de produção, reuniões de associações e comunitárias. Em suma, assegurar meios para as mulheres

\footnotetext{
7 “O Pronaf (Programa Nacional de Fortalecimento da Agricultura Familiar) foi criado em 1995 pelo governo federal com o objetivo de prestar um atendimento diferenciado aos pequenos agricultores - aqueles cuja produção é resultado de sua própria força de trabalho ou da mão de obra familiar". Disponível em: https:/ / blog.cresol.com.br/tudoque-voce-precisa-saber-sobre-o-pronaf/. Acesso em: 28 ago. 2020.

8 Financiamento à mulher agricultora integrante de unidade familiar de produção enquadrada no Pronaf, independentemente do estado civil. A concessão de crédito pode ser individual (uma produtora) ou coletiva (associação de produtoras). Disponível em: https://www.bndes.gov.br/wps/portal/site/home/financiamento/produto/pronafmulher. Acesso em: 28 ago. 2020.
} 
adquirirem relativa autonomia econômica (SOUSA; ALMEIDA; LEITÃO, 2017).

Afinal, conforme enfatiza a própria Aires Oliveira, o empoderamento feminino consiste na libertação do "jugo machista", ou seja, não se limita à conquista de autonomia econômica, que as políticas públicas podem contribuir para alcançarem, mas envolve um poder interior que emerge a partir da conscientização da opressão de gênero, aquisição de autoconfiança, controle sobre suas vidas, um maior campo de escolhas e possibilidade de maior acesso e controle sobre recursos para/pelas mulheres (SARDENBERG, 2010). Isso porque, de acordo com Ana Paula Oliveira, que ingressou no movimento sindical aos 18 anos, o machismo está presente nos sindicatos, cuja estrutura é androcêntrica, então, se a mulher é jovem e bonita, ela é alvo de preconceito e sua contribuição ao movimento posta à prova e, a partir da prática política, apresenta o seu próprio conceito de empoderamento:

Eu digo que a nossa caminhada é exemplo de várias pessoas que me fizeram assim e a gente tem nossa autonomia, nosso respeito, gostar de si próprio, saber que a gente é tão grande. As pessoas dizem que a mulher é o sexo frágil, mas a gente é tão grande, a gente consegue ser mãe, consegue ser mulher, consegue ser militante, tanta coisa ao mesmo tempo e a gente consegue agarrar tudo. E hoje quem mais me liga para pedir informação, por eu ter um certo tempo no sindicato, são os homens. Tenho dois companheiros no sindicato que é o tempo todo, eles até brincam comigo. Então eu me sinto muito bem quando um homem liga para mim e diz 'eu preciso, porque você entende mais disso'. A gente se sente importante naquele momento porque ele realmente conhece. Ele não está ligando para mim porque eu sou mulher; ele está ligando porque sabe que eu tenho uma qualificação, que eu tenho um conhecimento que ele não sabe para ele, então eu me sinto realizada (ANA PAULA OLIVEIRA). 
Ana Paula Oliveira fala de um poder que vem de dentro, da sua autoconfiança, autoestima, ou seja, sua capacidade de resistência e resiliência a cada desafio e oposição, do reconhecimento dos companheiros de sindicato e militância quanto aos seus conhecimentos e qualificação. Todavia, se houve mudanças, há também permanências e outros tantos desafios a serem enfrentados pelas mulheres trabalhadoras rurais, conforme discutiremos no próximo tópico.

\section{Encruzilhada final - mudanças, desafios e permanências}

\section{Mudanças}

Os depoimentos das entrevistadas exaltam as conquistas alcançadas pelas mulheres desde sua inserção no movimento sindical, em que a "cada dia [estão] conquistando espaço", explica Luciana Reis, principalmente quando "nós mulheres somos seres discriminados", isto é, ainda que trabalhem mais, continuam recebendo salários inferiores aos dos homens, têm menos prestígio e reconhecimento e, reforça seu ponto de vista: “Então é uma conquista quando uma mulher está numa diretoria de um sindicato ou em qualquer órgão", opinião compartilhada por Aires Oliveira:

De lá para cá a gente conquistou a paridade de gênero Hoje para um processo eleitoral de sindicato ser validado a gente precisa garantir que $50 \%$ do gênero feminino esteja como candidatas na chapa. Aqui em Sergipe é diferente. A gente conseguiu esse diferencial por conta do processo histórico. Hoje $80 \%$ das direções dos sindicatos e na federação a gente vê isso. $80 \%$ estão [sic] mulheres: presidentes, tesoureiras, secretárias-gerais, secretárias de juventude e o próprio cargo de coordenadora de mulheres. A gente percebe que é um avanço, mas a gente ainda está muito longe de conquistar participações iguais, condição salarial iguais (AIRES OLIVEIRA). 
Luciana Reis também aponta como uma grande conquista "o conhecimento", segundo ela "uma riqueza que ninguém toma", mas que pode "transmitir para outras companheiras". Como pondera Lúcia Moura, essa conquista se traduz sob a forma de "liberdade de você pensar e dizer o que pensa em alguns espaços e ajudar alguém. Você pensando em tanta liberdade de pensar, de ajudar e orientar", o que se configura como instrumento emancipatório dentro de um sistema alicerçado na dominação e opressão e, resulta tanto no empoderamento individual como coletivo, processo que se revela, de acordo com Berth (2019), não só necessário como inerente às lutas por emancipação sociopolítica, perpassadas por muitos desafios e outras tantas permanências, que certamente não são superadas apenas com a garantia da paridade de gênero no processo eleitoral, conforme discutiremos a seguir.

\section{Desafios e permanências}

O crescimento da participação das mulheres no movimento sindical de Sergipe é indiscutível, como coloca Ana Paula Oliveira, o "estado hoje tem cerca de $80 \%$ das diretorias e tem sindicatos como os de Malhador e Areia Branca que chegam a ter $90 \%$ da diretoria ser de mulheres". Mas, como ela mesma avalia, "às vezes a gente está lá em número" e, exerce cargos muitas vezes devido ao conhecimento de informática, ter mais domínio de leitura e letra mais bonita que os homens. Além disso, convivem com o machismo e têm sua qualificação posta à prova:

Por mais que o tempo passe, por mais que a gente esteja inseridas, eu tenho essa angústia ainda. [...] Aí fica um 'ah, a juventude quer ganhar os espaços. Essas mulheres agora quer tudo [sic]'. E aí fica a questão do machismo ainda porque é predominância 
mesmo [...] Mas, se a gente for fazer uma análise geral ainda eu não acho que hoje nossos companheiros não vão nos ouvir, eles sempre vão achar que a gente está aqui ocupando cotas, que a gente veio... a última palavra é a deles. [...]. Eu não estou na presidência do sindicato por cota; eu estou aqui por que eu me fiz e me criei, no foi do nada, porque sou bonitinha do cabelo liso. Eu fiz por merecer estar aqui, conquistei esse espaço. [...] Eu conquistei esse espaço e quero que as pessoas me respeitem por isso. A gente tem que se impor muito. Porque tem determinados espaço que fica 'ah, eu só quero jovens, só quero mulheres'. A gente tem que respeitar não só a idade, mas também o ser humano, cada um no seu jeito. Aí, nessa questão das mulheres, eu ainda sinto isso. A gente conquista nossos espaços, mas ainda coloca um dedinho lá e acha que é por causa de cota ou alguma outra coisa. Eles acabam fazendo isso. É como se eles estivessem nos dando alguma coisa... a gente conquista, mas eles têm que dar alguma explicação diferente (ANA PAULA OLIVEIRA).

Ainda que as mulheres ocupem cargos na diretoria dos sindicatos, inclusive assumam a presidência, percebe-se que as práticas discriminatórias persistem ${ }^{9}$, assim como comportamentos machistas que associam a inserção feminina no movimento à juventude e beleza, assim como sua participação é concebida pelos homens como favor, condescendência, o que desqualifica o trabalho desenvolvido pelas mulheres e lhes nega representatividade, na medida em que é reeditada a oposição binária masculino-feminino, entre produção-reprodução, público-privado etc. que define lugares e papeis aparentemente dotados de fixidez (LOURO, 1997) e, nessa lógica dicotômica a prioridade é

\footnotetext{
9 Esse não é um comportamento isolado e peculiar dos sindicatos sergipanos. Ao investigar as relações de gênero entre sindicalistas de Chapecó/Santa Catarina, Boni (2004, p. 300), acrescenta que: "No que se refere a poder, as dirigentes sindicais são categóricas ao afirmar que os homens não querem abrir mão de seus espaços e que, mesmo cedendo em alguns pontos, em outros mostram que na prática não estão dispostos a dividir o poder".
} 
conferida ao primeiro elemento, "do qual o outro se deriva" [grifo da autora], ou seja, a mulher ainda tem uma função secundária, associada à esfera doméstica, cabendo ao homem o poder de decisão, o comando. Nas palavras de Louro (1997, p. 33): “A lógica dicotômica carrega essa ideia. Em consequência, essa lógica supõe que a relação masculino-feminino constitui uma oposição entre um polo dominante e outro dominado - e essa seria a única e permanente forma de relação entre os dois elementos".

Essa lógica dicotômica está presente na relação conjugal e cria sérios conflitos entre os casais, pois, a mulher tem que conciliar as atividades na direção executiva dos sindicatos com os afazeres domésticos e reprodução do grupo familiar. Aires Oliveira exemplifica:

Olhe como é difícil viver no campo, eu vou usar um exemplo da minha casa. Eu tenho três filhos, eu sou liberada da atividade rural para representar a categoria na federação. Quando eu vou para o meu interior... meus três filhos estudam... mas olhe: cuidar das crianças e arrumar para ir para escola. Aí o companheiro vem e diz: 'vai vir trabalhador hoje para casa'. Aí a gente se organiza para alimentar os trabalhadores. Mas esse trabalho nosso nem sempre é valorizado e reconhecido pelos companheiros. É um dever da mulher cuidar das tarefas de casa. Ora, mas o homem come do mesmo jeito que a mulher, o homem suja muito mais do que a mulher. A gente ainda precisa de muitos espaços de formação e conscientização. Acho que não dá para romper esse sistema que nos oprime, nos explora, se a gente não tiver uma mudança de comportamento dos companheiros por que a prática é deles.

Observa-se que não há uma divisão equilibrada das tarefas domésticas, a mulher permanece como única responsável pelo cuidado com os filhos, desde a alimentação ao vestuário e deveres escolares; pelos afazeres relativos à casa - arrumação e limpeza; pelo bem-estar do companheiro. Em suma, o principal papel das mulheres ainda permanece como esposa-mãe e, portanto, não é fácil conciliar as 
obrigações no âmbito privado-familiar com a militância e o trabalho na direção executiva dos sindicatos, até porque é como se estivesse abandonando um espaço - a casa e um papel que é intrínseco à natureza feminina e invadindo um espaço público, de poder, reservado ao homem. Por essa razão, Aires Oliveira reforça a importância da criação de espaços de formação e conscientização voltados tanto para as mulheres quanto homens trabalhadores rurais e, acrescenta:

O nosso grande desafio é dialogar com a sociedade. Eu me reporto muito à marcha porque o movimento sindical de trabalhadores e trabalhadoras rurais tem as pautas, atua nos municípios, atua no estado, na nacional, mas ela tem uma dimensão para além do movimento porque ela dialoga com todos os setores da sociedade. É mulher? Pode ser rica, pobre, negra, quilombola, indígena, branca: ela sofre na sua condição de ser mulher. Então esse sentimento de buscar as mulheres para se libertarem dessa condição, superar essa situação, perpassa pela organização política da Marcha das Margaridas. É dialogar sobre o que a gente tinha, sobre o que a gente tem, sobre o que a gente quer. É reconstruir um Brasil com soberania com democracia sem violência, que promova a oportunidade das mulheres, mas também que reconheça que não é só promover oportunidade, mas a gente precisa estar nos cargos de decisão e de poder, desde a esfera privada até a esfera pública (AIRES OLIVEIRA).

Lúcia Moura, Aires Oliveira, Gedalva Fonseca, Ana Paula Oliveira e Luciana Reis assim como outras mulheres são todas Margaridas, enfrentam preconceito e discriminação, mas não esmorecem, seguem em Marcha na luta por uma sociedade mais justa e igualitária, sem opressão e exploração, em que as mulheres possam exercitar a autonomia, a liberdade e, em tempos tão difíceis e eivados por incertezas como os que estamos vivendo, elas são mais do que necessárias, são indispensáveis se quisermos reconstruir um Brasil soberano, em que a democracia vença a violência que nos enreda e 
embrutece em suas múltiplas formas e, que torne reais os direitos iguais entre homens e mulheres preconizados em nossa Constituição Cidadã, desde a esfera privada à esfera pública.

\section{Referências}

AMORIM, Érika Oliveira; EUCLIDES, Maria Simone; FILHO, Barduni Jairo; FIÚZA, Ana Louise de Carvalho. Sindicalizadas Rurais e ativistas Políticas: fatores de empoderamento da mulher no meio rural? In: Congresso Latino americano de Sociologia Rural, VIII., 2010, Recife. Anais [...]. América Latina: realineamientos politicos y proyectos en disputa, 2010.

BERTH, Joice. Empoderamento. São Paulo: Sueli Carneiro; Pólen, 2019. 18 p. (Coleção Feminismos Plurais/Coord. Djamila Ribeiro).

BONI, Valdete. Poder e igualdade: as relações de gênero entre sindicalistas rurais de Chapecó, Santa Catarina. Estudos Feministas, Florianópolis, v. 12, n. 1, p. 289-302, jan./abr. 2004.

BRASIL. Ministério do Desenvolvimento Social e Combate à Fome. Secretaria Nacional de Assistência Social. Política Nacional de Assistência Social (PNAS). Brasília: Ministério do Desenvolvimento Social e Combate à Fome/Secretaria Nacional de Assistência Social, 2004.

BRASIL. Censo Demográfico 2010. Rio de Janeiro: MPOG/IBGE, 2010. Disponível em: https://censo2010.ibge.gov.br/. Acesso em: 30 ago. 2020.

CADERNO de textos para estudos e debates - Marcha das Margaridas 2015. Secretaria de Mulheres Trabalhadoras Rurais da CONTAG. 2015.

CARNEIRO, Maria José. Mulheres no campo: notas sobre sua participação política e a condição social do gênero. Estudos Sociedade e Agricultura, v. 2, n. 1, junho 1994, p. 11-22. 
CARNEIRO, Maria José; TEIXEIRA, Vanessa Lopes. Mulher rural nos discursos dos mediadores. Estudos Sociedade e Agricultura, v. 5, p. 4557, nov. 1995.

FRANCO, Maria Asenate Conceição. Será o homem a cumeeira da casa? Ou sou dona do meu próprio nariz? Violência contra mulheres rurais na Bahia. 2018. Tese (Doutorado em Estudos Interdisciplinares sobre Mulheres, Gênero e Feminismo) - Faculdade de Filosofia e Ciências Humanas, Universidade Federal da Bahia. Salvador, 2018.

MENEZES, Sônia de Souza Mendonça; ALMEIDA, Maria Geralda de. Reorientações produtivas na divisão familiar do trabalho: o papel das mulheres do sertão do São Francisco (Sergipe) na produção de queijo coalho. In: NEVES, Delma Pessanha; MEDEIROS, Leonilde Servolo de (Org.). Mulheres camponesas. Niterói: Alternativa, 2013. p. 129-146.

SAFFIOTI, Heleieth Iara Bongiovani. Gênero, patriarcado, violência. São Paulo: Editora Fundação Perseu Abramo, 2004.

SARDENBERG, Cecília M. B. Da transversalidade à transversalização de gênero aportes conceituais e prático-políticos. In: ALVES, Ivia; SCHEFLER, Maria de Lourdes; AQUINO, Petilda Serva Vasquez e Silvia de (Org.). Travessias de gênero na perspectiva feminista. Salvador: EDUFBA/NEIM, 2010. p. 37-73. (Coleção Bahianas; 12)

SOUSA, Gerlúcio Moura Bezerra de; ALMEIDA, Maria das Graças Andrade Ataíde de; LEITÃO, Maria do Rosário de Fátima Andrade. Gênero e acesso ao crédito rural na Associação Municipal Mulher Flor do Campo em Pernambuco. Extensão Rural, DEAER - CCR - UFSM, Santa Maria, v. 24, n. 4, p. 31-47, out./ dez. 2017.

LOURO, Guacira Lopes. Gênero, sexualidade e educação. Uma perspectiva pós-estruturalista. 6. ed. Petrópolis, RJ: Vozes, 2003.

THAYER, Millie. Feminismo transnacional: re-lendo Joan Scott no sertão. Estudos Feministas, Florianópolis, v. 9, n. 1, p. 103-130, 2001.

TOLEDO, Cecília. Mulheres: o gênero nos une, a classe nos divide. 2. ed. Apresentação: Claudia Mazzei Nogueira. São Paulo: Sundermann, 2008. 152p. 